\section{Exemplary Shared Standards Among Professionals}

\section{Competence}

The people whom we serve as professionals assume that we are competent to do what we are called to do, even in a disaster. Yet, we very well may find ourselves ill-prepared for some of the specific situations we may encounter. For example, a paramedic may be required to make medical decisions that go beyond his or her training or prior experiences. A mental health worker may be required to intervene in a situation of suicidality without specific training or prior experience in such.

As professionals, most of us have ethical guidelines regarding competence that limit our actions to those for which we are fully qualified by education, training, and/or experience. However, in a disaster, we may find ourselves called upon to serve in ways that push the boundaries of that education and experience. Furthermore, at the time, we may not have access to a colleague who more appropriately could serve the disaster victim, or at least offer consultation or supervision.

\section{Confidentiality}

Most professionals are bound ethically by a principle of confidentiality in relationships with those served. What happens to this principle when one literally is working "in the trenches?" In a disas- ter, one rarely is working alone with one victim. In fact, more often than not, one is working in the open with a crowd or in a makeshift facility with little to no privacy. Mental health workers may find themselves doing "curb-side counseling." Any worker may find him or herself being interviewed by the media. What minimal parameters are we going to set with respect to confidentiality? Is it practical to aspire to any in the midst of such life and death drama as may occur?

\section{Duties}

Special duties may accompany professional service. This might include the duty to warn others if an individual is potentially harmful to self or others. It might include the duty to report potentially harmful or illegal activity. At the very least, our efforts may include the duty to do no harm.

\section{Transitioning for Local Long-Term Service} In our effort to do no harm, we might ask ourselves what effects obtain not only from our actions, but also from our leaving at the end of our service. Most professionals volunteering in a disaster only will be able to participate in recovery efforts for a very limited time. What responsibilities do we have to the individuals whom we have met, aided, and served in a professional capacity? How do we assure ourselves that they will con- tinue to be provided the service that we have begun? One of the common ethical principles we share in one form or another, is the principle of interdisciplinary cooperation. It follows that individually we have an obligation to work smoothly with members of other professions and with our local counterparts. Individual and inter-agency cooperation becomes paramount when we are transitioning from external to local service. Making that transition is an ethical obligation for each of us as professionals. We must not simply assume that "someone will take care of it," or that "I did what I could, now it's someone else's turn."

\section{Excellence Through Ethics}

It is certain that disasters always will exist and, it is clear that ethical dilemmas will accompany these. As research data bases increase and theoretical models are being developed to guide our actions in disaster work, I encourage us also to look to our respective ethical codes to provide guidance for how that work will be practiced. It is one thing to conduct our professional work within the confines of a physically and emotionally structured environment. It is another to maintain the highest standards of our practice in the midst of a disaster. Those whom we serve always deserve our utmost professionalism. This is no less true in times of chaos.

\title{
Lessons Learned from Research at Three-Mile Island and Goiania, Brazil
} Daniel L. Collins, PhD

Lt. Colonel, United States Air Force Office of Scientific Research, Bolling AFB, D.C. USA

The views expressed are those of the author and do not reflect an official United States Air Force position.

A summary of the research findings associated with two ionizing radiation accidents were presented. The first accident occurred at Three Mile Island (TMI) in Pennsylvania and the second accident occurred in South America at Goiania, Brazil. The knowledge from these two unfortunate incidents pro- vides an interesting examination of the human stress response associated with ionizing radiation accidents. The knowledge obtained from the TMI accident (where very little, if any, radiation was released) was extended by studying the Goiania, Brazil accident (where four people died from radiation exposure).

More than 15 years have passed since the first major nuclear power plant accident in the United States occurred at Three Mile Island, Goldsboro, Pennsylvania. Understanding the psychological after-effects requires a thorough knowledge of the temporal antecedents, because they are an essential internal component of the Three Mile Island accident. Therefore, this presentation described the Three Mile Island accident; reviewed the major events preceding the psychological studies; and summarized the major psychological, behavioral, and neuroendocrine findings of field studies of the Three Mile Island residents.

The research findings at Three Mile Island were extended by studying the psychological stress sequel associated with an ionizing radiation accident, where a significant amount of radiation was released. At the invitation of the Brazilian government, a multidisciplinary field study was conducted in Goiania, Brazil, 3 1/2 years after an accident 
involving ${ }^{137} \mathrm{Cs}$, a radioactive cesium isotope. The authors compared subjects exposed to low levels of ionizing radiation, subjects who experienced anticipatory stress from fear of radiation exposure, and a non-irradiated control group.
Results indicated the presence of chronic stress, as measured by psychological, behavioral, and neuroendocrine indices, in subjects who were exposed as well as in subjects fearful of potential radiation exposure. Anticipatory stress associated with potential exposure to ionizing radiation resulted in a level of stress similar to that from actual exposure to ionizing radiation. These findings have implications for past and future radiation accidents.

\section{References}

Collins DL, Engel RE, Grundl JA, et al: Balancing radiation benefits and risks; The needs of an informed public. Committee on Interagency Radia tion Research and Policy Coordination (CIRRPC). Subpanel on Public Education, Washington, DC, 1994

Collins DL, Carvalho AB: Chronic stress from the Goiania $137 \mathrm{Cs}$ radiation accident. Behavioral Medicine 1993;18:149-157.

Collins DL: Behavioral differences of irradiated persons associated with the Kyshtym, Chelyabinsk and Chemobyl nuclear accidents. Military Medicine 1992;157:548-552.

Collins DL: Stress at Three Mile Island: Altered perceptions, behaviors and neuroendocrine values, In: The Medical Basis for Radiation Accident Pre paredness III: Psychological Perspectives (ed) Ricks RC, Berger ME, Elsevier Press, New York
1991. pp 71-80.

Persistence of Differences Between Three Mile Island Residents and a Control Group. Defense Technical Information Center. AD-A145567 Alexandria, Virginia, 1984.

Collins DL, Baum A, Singer JE: Coping with stress at Three Mile Island: Psychological and biochemical evidence. Health Psychology 1983;2:149-166.

\section{COLLABORATION FOR SERVICE DELIVERY AND FOR RESEARCH}

\section{Collaboration with Local Mental Health Groups: Sending in Mental Health Teams}

\section{Gerard A. Jacobs, PhD}

Director, Disaster Mental Health Institute, University of South Dakota, Vermillion, South Dakota USA

Whenever external disaster mental health teams enter a community, it is important that they interface effectively with the community's pre-existing mental health agencies. This paper addresses strategies used in two different interventions. The first intervention to be described will be Project Recovery, South Dakota's [U.S.] Federal Emergency Management Agency (FEMA)funded, flood crisis intervention. The second will be the American Red Cross's (ARC) intervention in the aftermath of the crash of Flight 427 in September.
Project Recovery was funded by two FEMA grants, an Immediate Services Grant, that continued for eight months after the presidential disaster declaration, and a Regular Services Grant, that is proceeding for an additional nine months. In developing this intervention program, community mental health centers in the affected region were consulted. Changes in funding structure, however, had reduced their flexibility and ability to respond fully to the flood emergency. It became necessary, therefore, to design an intervention program that could provide a long-term interface with the existing mental health system without threatening the existing system and without wasting available funds by duplicating services.
The disaster mental health response to the crash of Flight 427 which was addressed was an American Red Cross's (ARC) intervention. Aspects of it were typical of American Red Cross's (ARC) disaster response, while others were relatively unique. The intervention was relatively brief, and was designed to address the immediate needs of those affected by the disaster. The role of the ARC team was in support of the local mental health community. The division of labor and collaboration were outlined. Principles and challenges in ensuring a smooth working relationship with local resources were discussed. The paper also discussed how these principles can be employed in more typical ARC disaster responses.

\section{Mental Health Training Programs and Clinical Services in Armenia after the 1988 Earthquake} Louis M. Najarian, $M D$

\section{Clinical Assistant Professor of Psychiatry and Pediatrics, Cornell University Medical College, North Shore University Hospital, Manhasset, New York USA}

The earthquake in Armenia on 07 December 1988 offered mental health professionals in the United States the opportunity to provide direct psychotherapeutic treatment to individuals suffering from the trauma of the disas- ter. It also offered training in American psychotherapeutic methods to mental health professionals in Armenia. The delivery of service in the earthquake zone became a model to teach methods of crisis intervention. The model eventually impacted on the delivery of mental health services in the entire country.

Countries worldwide responded to the devastating earthquake in Armenia by providing humanitarian aid such as food, clothing, reconstruction materials, medical supplies, and psychological intervention. The French government in particular, arrived the day after the earthquake and eventually provided psychological help to children by establishing clinics with French speaking psychologists who conducted therapy via interpreters. The Psychiatric Outreach Program (POP), established by the Armenian Relief Society, an Americanbased Armenian organization offering humanitarian aid to needy Armenians worldwide, provided financial support for American mental health profession- 